\title{
Suicidal Idea, ADHD, Depression, Anxiety, Self-esteem and Impulsiveness in Korean Soldiers
}

\author{
Na Ye Kim¹, Pyo Kyu Lee ${ }^{2}$ and Myung Ho Lim* \\ ${ }^{1}$ Aram Medical Hospital, Asan, South Korea \\ ${ }^{2}$ Department of Marine Corps Military Studies, Dankook University, Cheonan, South Korea \\ ${ }^{3}$ Department of Psychology, Dankook University, Cheonan, South Korea
}

\begin{abstract}
Objective: This study aimed to evaluate the prevalence rates of ADHD, depression, and anxiety as well as suicidal ideation of soldiers for the first time in Korea. Also, it examined the associations with ADHD, depression, anxiety, and self-esteem between suicide idea group and the comparison group.

Methods: A set of questionnaires was provided to a total of 414 participants ( 80 with higher suicide idea and 334 without suicide idea) from November 2014 to January 2015. All of participants were evaluated using the Korean Adult Attention Deficit Hyperactivity Disorder Scales, Beck's Depression Inventory, Beck's Anxiety Inventory, Baratte' Impulsivity Scale, and Rosenberg's Self-esteem Inventory.

Result: The results of this study indicated that suicide risk group is related to ADHD and depression.

Conclusions: For the treatment of suicide in soldiers, effective evaluation and treatment of ADHD, as well as depression, seem to be necessary.
\end{abstract}

Keywords: Military camp; Depression; Anxiety; ADHD; Selfesteem; Impulsivity

\section{Introduction}

Most Korean men join the army after high school graduation or during the freshman or sophomore year at college based on the conscription. Accordingly, they generally belong to a young age group of about 19-24 years old [1]. This is a period in which selfidentity is forming; and they are physically mature but have immature interpersonal relations due to heavy study for entrance examination before college admission.

Adolescents who have joined the army experience a kind of culture shock from military life which is very different from the condition before joining the army and which imposes obedience, group behavior, homogeneity, and uniformity [2]. Due to the confusion from this difference between the military life and the school and social life before joining the army and the discrepancy in the sense of reality, soldiers show maladaptive symptoms such as anxiety, expression of loneliness, and lack of self-control, and much stress is caused by the military life that is not related with one's own future, compulsory obedience, poor welfare, and physical fatigue [3]. In addition, this is a period in which a lot of psychiatric diseases could occur. Soldiers should live in a closed group that requires strict discipline and control during this period. Therefore, they have a high possibility of experiencing serious stress, and could have difficulties in adapting to organized life $[4,5]$. Also, they could experience emotional problems such as depression, anxiety, inattention, impulsiveness, and suicidal ideation. In Korea, suicide has become a serious social problem since the mid-2000s. According to the 2012 data of the Statistics Korea, the suicide rate in Korea was 38 per 100,000 people, which showed the highest prevalence rate among the OECD member countries; and the suicide rate in Korea has rapidly increased compared to those in Western countries [6,7]. Also, the proportion of suicide among the causes of death in Korea has gradually increased. In particular, the suicide rates of those in their 20 s and 30s have rapidly increased, and suicide and self-injury ranked first among the causes of death for teenagers and those in their $20 \mathrm{~s}$ and 30 s as of 2015. Suicide is a major cause of death in military camps as well as the general society [8]. In military camps, 1,225 people were killed in military discipline accidents and safety-related accidents for 10 years (from 2004 to 2013); and among them, 774 people lost their lives in suicide incidents [9]. According to previous research, it is known that suicide is associated with psychiatric disorders such as depressive disorder, bipolar disorder, substance abuse, personality disorder, and impulse control disorder $[10,11]$. It has been reported that suicide is associated with ADHD [12,13] but it has also been reported that there was no association between suicide and ADHD [14]. As mentioned above, the association between suicide and depressive disorder is well known, but the association between suicide and ADHD has been insufficiently studied. It is known that the prevalence rate of childhood ADHD is $5-10 \%$, and $50-65 \%$ of them are also maintained in adulthood [15]. However, it has been reported that adult ADHD shows patterns different from those of childhood ADHD, in terms of diverse characteristics and prognosis of the disease. Adult ADHD shows decreased hyperactivity symptoms compared to childhood ADHD, and the major symptoms are inattention and impulsiveness. Also, for adult ADHD, difficulties in interpersonal relations, frequent traffic violation, and economic failure could be additionally observed. Due to the nature of the disease, adult ADHD as well as depressive disorder and anxiety disorder could experience more difficulties in military life that requires organized life [16]. Bahn et al. [17] mentioned that adult ADHD has a high possibility of experiencing difficulties in employment and military

*Corresponding author: Myung Ho Lim, Dandae Rho 119, Cheonan, South Korea, Tel: 82-41-550-3263; Fax: 82-41-550-3260; E-mail: paperose@dku. edu

Received May 29, 2015; Accepted July 29, 2015; Published August 03, 2015

Citation: Kim NY, Lee PK, Limm MH (2015) Suicidal Idea, ADHD, Depression, Anxiety, Self-esteem and Impulsiveness in Korean Soldiers. J Psychiatry 18: 314 doi: 10.4172/2378-5756.1000314

Copyright: (c) $2015 \mathrm{Kim}$ NY, et al. This is an open-access article distributed under the terms of the Creative Commons Attribution License, which permits unrestricted use, distribution, and reproduction in any medium, provided the original author and source are credited 
life due to the deficiency of executive function. However, in Korea, there is a lack of awareness of adult ADHD, and few relevant studies have been previously performed. Therefore, there has been no study on the prevalence rate of adult ADHD in military camps and on the difficulties that adult ADHD experiences. The object of this study was to investigate the prevalence rates of $\mathrm{ADHD}$, depression, and anxiety as well as suicidal ideation in soldiers for the first time in Korea. Also, the associations with ADHD, as well as depression, anxiety, and self-esteem were analysed.

\section{Methods \\ Participants}

A clinician explained the intent and purpose of this study to soldiers in OO located in Cheonan from November 2014 to January 2015 , and the all subject group was selected based on consultation with soldiers who had consented to fill out a survey. We had divided all subjects into two group; the suicide risk group $(\mathrm{N}=80$, above the score 3 of Beck Suicide Idea Scale) and the comparison group $(\mathrm{N}=334$, bellow the score 2 of Beck Suicide Idea Scale) included 414 soldiers residing in the research target area. Cheonan area that located in this military camp, was a metropolitan city with population about 500,000 .

\section{Instruments}

Epidemiological questionnaire: The history questionnaire contains questions on sex, age, socioeconomic status and recent academic or work achievement.

Scale for suicide ideation (SSI): The Suicide Intent Scale (SIS) was developed in order to assess the severity of suicide attempts. The scale consists of 15 questions which are scaled from 0-2, which take into account both the logistics of the suicide attempt as well as the intent. This scale was developed by Beck et al. [18] and translated into Korean by Shin et al. [19], and the reliability and validity were studied. The scales, with 18 items, is quantificated for suicide idea as sum of total score.

Korean Adult Attention Deficit Hyperactivity Disorder Scales (K-AADHS): Developed by Murphy and Barkley [20] based on the DSM-IV diagnostic criteria for adult ADHD, K-AADHS is used for assessment by self-reported form. The scales, with 18 items, is proven for its validity in differentiating adult with ADHD from those without, and designed to effectively differentiating three subtypes of ADHD: predominantly inattentive, predominantly hyperactive-impulsive, and combined hyperactive-impulsive and inattentive. Korean standardization has been achieved by Kim et al. [21], Cronbach alpha of total K-AADHS scale was 0.85 .

Beck's Depression Inventory (BDI): This BDI, one of the most widely used instruments for measuring the severity of depression was developed by Beck [22]. Lee and Song [23] classified scores over 16 as mild depressive state, internal reliability was 0.89 .

Beck's Anxiety Inventory (BAI): This is a useful assessment tool to measure anxiety clinically. It is useful in identify clinically anxious group and psychiatric patients and it also has the advantage to measure the anxious state of normal adults without psychiatric disorder. It was developed by Beck et al. [24] and translated into Korean by Yook and Kim [25], and the reliability and validity were studied. In the case of anxiety inventory scale, the scores $22-26$ indicate a little high anxiety, scores $27-31$ indicate a considerably very high anxiety, and scores 32 or higher indicate extremely high anxiety.
Rosenberg's self-esteem Inventory (RSI): Rosenberg's self-esteem inventory is a test for measuring the degree of self-esteem and the pattern of self-acceptance for an individual, and is known as a tool for measuring overall self-esteem. The inventory was devised in 1965 by Rosenberg in the United States, and Lee et al. [26] adapted it to Korean circumstances. It consists of a total of 10 questions (five questions on positive self-esteem and five questions on negative self-esteem) in a self-report format. Zero to three points is assigned to one question, and the range of the total score is $0-30$ points. A high score indicates high self-esteem, and the reliability was 0.79 in previous research $[27,28]$.

Impulsiveness scale (Barratt Impulsiveness Scale, BIS): The scale was developed by Barratt et al. for the measurement of impulsiveness, and Lee et al. [29] adapted it to Korean circumstances. It consists of 23 questions, and three subordinate factors: six questions for measuring cognitive impulsiveness (e.g., "I easily lose interest when thinking of complicated things"), eight questions for measuring motor impulsiveness (e.g., "It is hard to be seated on a spot for a long time"), and nine questions for measuring non-planning impulsiveness (e.g., "I start another task before finishing a task"). Likert-type four-point scale was used, where the score ranged from 'It never does' (1 point) to 'It always does' (4 points). A higher score represents higher impulsiveness. The Cronbach a coefficient at the time of the test development was 0.82 , which were relatively stable [30].

\section{Ethical consideration}

The present study was approved by the Institutional Review Board of Dankook university hospital (DK-2014-02-004). We obtained written informed consent from all participants before this entire study was carried out. We had full explanation verbally short form document information and this entire study's purpose and procedure with participants directly. Also we obtained the participant's voluntary agreement to participate.

\section{Statistics}

The data were processed using SPSS 15.0 (Korean version). In the statistical analysis, a cross tabulation analysis was performed for epidemiologic survey evaluation as necessary. The dependent variables of this study was suicide idea, the independent variables were ADHD, depression, anxiety, self-esteem, and impulsivity symptoms. For the analysis of the SSI, K-AADHS, BDI, BAI, BIS, and RSI score between both groups, a t-test were used. Also, to compare the frequencies among the ADHD, depression, anxiety, impulsivity and low esteem risk group which had a score higher than a cut-off point, a chi-square test was used. When the $\mathrm{p}$-value was less than 0.05 , it was considered significant.

\section{Results}

\section{Demographic characteristics of the study subjects}

The final study subjects were 414 people and all men. The suicide idea group was decided with $20 \%$ (above the score of 3 ) of the subjects ( 80 men), the lower $80 \%$ (below the score of 2) were classified as the comparison group (334 men). The average age of suicide idea group was $21.03 \pm 1.36$ years old, and the average age was $20.82 \pm 1.10$ where there was no significant difference $(\mathrm{F}=1.94, \mathrm{p}=.164)$ (Table 1$)$.

The suicide idea group had a total K-AADHS score of $28.85 \pm$ 9.26, and the comparison group had a total K-AADHS score of 23.39 \pm 4.77 . There was a significant difference between both groups $(\mathrm{F}=54$. $64, \mathrm{p}=0.000)$. The suicide idea group had a total BDI score of $10.06 \pm$ 9.41, and the comparison group had a total BDI score of $2.60 \pm 2.96$. 
Thus, there was a significant difference between both groups $(\mathrm{F}=149$. $09, \mathrm{p}=.000)$. The suicide idea group had a total SSI score of $10.31 \pm$ 6.90 , and the comparison group had a total SSI score of $0.47 \pm 0.67$. Thus, there was a significant difference between both groups $(\mathrm{F}=658$. 07, $\mathrm{p}=.000$ ). The suicide idea group had a total BAI score of $8.26 \pm$ 10.05 , and the comparison group had a total BAI score of $2.46 \pm 3.43$. Thus, there was a significant difference between both groups $(\mathrm{F}=75.06$, $\mathrm{p}=.000$ ). The suicide idea group had a total RSI score of $28.79 \pm 6.08$, and the comparison group had a total RSI score of $33.88 \pm 4.01$. Thus, there was a significant difference between both groups $(\mathrm{F}=83.27, \mathrm{p}=$. 000). The suicide idea group had a total BIS-II score of $50.55 \pm 11.66$, and the comparison group had a total BIS-II score of $45.09 \pm 9.64$. Thus, there was a significant difference between both groups $(\mathrm{F}=18.45, \mathrm{p}=$. 000) (Table 2).

The suicide idea group had a self-esteem risk subjects of 44 people (55.0\%), and the comparison group had a self-esteem risk subjects of 57 people (17.2\%). Thus, there was a significant difference between both groups $(\mathrm{F}=49.86, \mathrm{p}=.000)$. The suicide idea group had a impulsiveness risk subjects of 32 people (41.0\%), and the comparison group had a impulsiveness risk subjects of 72 people $(22.4 \%)$. Thus, there was a significant difference between both groups $(\mathrm{F}=11.26, \mathrm{p}=.001)$. The suicide idea group had a depression risk subjects of 21 people $(26.6 \%)$, and the comparison group had a depression risk subjects of 0 people (0\%). Thus, there was a significant difference between both groups $(\mathrm{F}=93.54, \mathrm{p}=.000)$. The suicide idea group had a anxiety risk subjects of 7 people (8.8\%), and the comparison group had a anxiety risk subjects of 2 people $(0.6 \%)$. Thus, there was a significant difference between both groups $(\mathrm{F}=20.16, \mathrm{p}=.000)$. The suicide idea group had a ADHD risk subjects of 13 people (16.3\%), and the comparison group had a ADHD risk subjects of 5 people (1. 5\%). Thus, there was a significant difference between both groups $(\mathrm{F}=33.78, \mathrm{p}=.000)$ (Table 3$)$. As a result, the suicide idea group showed significantly high correlations with

\begin{tabular}{|c|c|c|c|c|}
\hline Rating Scale & $\begin{array}{l}\text { Suicide idea } \\
\text { group }(n=80)\end{array}$ & $\begin{array}{c}\text { Comparison } \\
\text { group }(n=334)\end{array}$ & $F$ or $x^{2}$ & $p$ value \\
\hline & Mean \pm S.D. & Mean \pm S.D. & & \\
\hline $\mathrm{Age}^{\mathrm{a}}$ & $21.03 \pm 1.36$ & $20.82 \pm 1.10$ & 1.94 & \\
\hline $\begin{array}{l}\text { Recent academic } \\
\text { achievement }(\mathrm{N}, \%)^{\mathrm{b}}\end{array}$ & $10(12.8 \%)$ & $42(12.7 \%)$ & 0.261 & \\
\hline High & $47(60.3 \%)$ & $208(63.0 \%)$ & & \\
\hline Middle & $21(26.9 \%)$ & $80(24.2 \%)$ & & \\
\hline Low & & & & \\
\hline
\end{tabular}

Table 1: Epidemiological characteristics between suicide idea group and comparison group.

\begin{tabular}{|l|c|c|l|l|}
\hline $\begin{array}{c}\text { Rating } \\
\text { Scale }\end{array}$ & $\begin{array}{c}\text { Suicide idea group } \\
(\mathbf{n = 8 0}) \text { Mean } \mathbf{\text { S.D. }}\end{array}$ & $\begin{array}{c}\text { Comparison group } \\
(\mathbf{n = 3 3 4 )} \text { Mean } \mathbf{\text { S.D. }}\end{array}$ & $\mathbf{F}$ & $\begin{array}{l}\mathbf{p} \\
\text { value }\end{array}$ \\
\hline SSI & $10.31 \pm 6.90$ & & 658.07 & .000 \\
\hline BDI & $10.06 \pm 9.41$ & $0.47 \pm 0.67$ & 149.09 & .000 \\
\hline BAI & $8.26 \pm 10.05$ & $2.60 \pm 2.96$ & 75.06 & .000 \\
\hline K-AADHS & $28.85 \pm 9.26$ & $2.46 \pm 3.43$ & 54.64 & .000 \\
\hline Inattention & $15.09 \pm 5.01$ & $23.39 \pm 4.77$ & 54.17 & .000 \\
\hline Hyperactivity & $28.79 \pm 6.08$ & $11.38 \pm 2.52$ & 37.75 & .000 \\
\hline RSI & $50.55 \pm 11.66$ & $33.88 \pm 4.01$ & 83.27 & .000 \\
\hline BIS & $13.82 \pm 3.31$ & $45.09 \pm 9.64$ & 18.45 & .000 \\
\hline Cognitive & $17.27 \pm 5.65$ & $12.69 \pm 2.83$ & 9.34 & .002 \\
\hline Behavioral & $19.46 \pm 4.32$ & $14.88 \pm 4.55$ & 15.72 & .000 \\
\hline Unplanned & $19.46 \pm 4.32$ & $17.53 \pm 4.08$ & 13.78 & .000 \\
\hline
\end{tabular}

Table 2: Suicide idea, depression, anxiety, ADHD, self-esteem, impulsivity between Suicide Idea Group.

Note: independent $t$ test, $a$ or chi-square test,b $\mathrm{p}$ value $<.05$. Comparison Group. Note: Analysis of Variance, $p$ value $<.05$.
ADHD, depression, anxiety, self-esteem, and impulsiveness symptoms (Table 4). In the logistic regression model of the suicide idea group and the comparison group, the relative risk of Depression was 2. 55 times higher (confidence interval 1.23-5.30), which showed a statistical significance $(\mathrm{x} 2=6.33, \mathrm{p}=.012)$. The relative risk of ADHD was 2.37 times higher (confidence interval 1.16-4.83), which also showed a statistical significance $(\mathrm{x} 2=5.60, \mathrm{p}=.018)$ (Table 5).

\section{Discussion}

In this study, the associations of suicide idea, ADHD, depression, anxiety, impulsiveness, and self-esteem were examined for soldiers. In soldiers in this study, there were significant differences in the depression, anxiety, ADHD, impulsiveness and self-esteem between the suicide idea group and the general control group. As a result, the suicide idea group showed significantly high correlations with ADHD, depression, anxiety, self-esteem, and impulsiveness symptoms; and after a regression analysis, it still showed a significant correlation with depression and ADHD symptoms. Thus we confirmed our hypothesis that Korean soldiers with suicide idea have the association of ADHD

\begin{tabular}{|l|c|c|c|c|}
\hline Rating Scale & $\begin{array}{c}\text { Suicide idea group } \\
(\mathbf{n = 8 0 )}\end{array}$ & $\begin{array}{c}\text { Comparison group } \\
(\mathbf{n = 3 3 4 )}\end{array}$ & $\mathbf{X}^{\mathbf{2}}$ & $\begin{array}{c}\mathbf{p} \\
\text { value }\end{array}$ \\
\hline BDI (>16) & $\mathbf{N}(\mathbf{\%})$ & $\mathbf{N}(\mathbf{\%})$ & & \\
\hline BAI (>22) & $21(26.6 \%)$ & $0(0 \%)$ & 93.54 & 0 \\
\hline K-AADHS & $13(8.8 \%)$ & $2(0.6 \%)$ & 20.16 & 0 \\
\hline Inattention & & $5(1.5 \%)$ & 33.78 & 0 \\
\hline Hyperactivity & & & & \\
\hline RSI & $44(55.0 \%)$ & $57(17.2 \%)$ & 49.86 & 0 \\
\hline BIS & $32(41.0 \%)$ & $72(22.4 \%)$ & 11.26 & 0.001 \\
\hline Cognitive & & & & \\
\hline Behavioral & & & & \\
\hline Unplanned & & & & \\
\hline
\end{tabular}

Table 3: Suicide idea, depression, anxiety, ADHD, self-esteem, impulsivity between suicide idea group and comparison group. Note: Chi-square test, $p$ value $<.05$.

\begin{tabular}{|l|l|l|l|l|l|l|l|}
\hline Rating Scales & 1 & 2 & 3 & 4 & 5 & 6 & 7 \\
\hline SSI & - & & & & & & \\
\hline BDI & $.41^{* *}$ & & & & & & \\
\hline BAI & $.22^{* *}$ & $.26^{* *}$ & & & & & \\
\hline K-AADHS & $.31^{* *}$ & $.42^{* *}$ & $.22^{* *}$ & & & & \\
\hline RSI & $.35^{* *}$ & $.52^{* *}$ & $.22^{* *}$ & $.36^{* *}$ & & & \\
\hline BIS & $.17^{* *}$ & $.36^{* *}$ & $.20^{* *}$ & $.47^{* *}$ & $.42^{* *}$ & & \\
\hline AC & 0.02 & 0.05 & 0.03 & $.18^{* *}$ & $.10^{*}$ & $.21^{* *}$ & - \\
\hline
\end{tabular}

1: SSI; Scales of Suicide Idea, 2: BDI; Beck's Depression Inventory, 3: BAI; Beck's Anxiety Inventory, 4: K-AADHS; Korean Adult Attention Deficit Hyperactivity Disorder Scales, 5: RSI; Rosenberg's self-esteem inventory, 6: BIS; Baratte's Impulsivity Scale, 7: AC; Academic achievement or work achievement. Note: Bivariate Correlation, $\mathrm{p}$ value $<.05$

Table 4: Bivariate correlation between the main independence variables (BDI, BAI, K-AADHS, RSE, BIS) and the dependence variable (Suicide Idea).

\begin{tabular}{|l|c|c|c|c|c|}
\hline & $\begin{array}{c}\text { Parameter } \\
\text { estimate }\end{array}$ & $\begin{array}{c}\text { Standard } \\
\text { error }\end{array}$ & Chi-square & $\begin{array}{c}\mathbf{p} \\
\text { Value }\end{array}$ & Odds ratio \\
\hline BDI & .94 & .37 & 6.33 & .012 & $2.55(1.23-5.30)$ \\
\hline K-AADHS & .86 & .36 & 5.60 & .018 & $2.37(1.16-4.83)$ \\
\hline RSI & .50 & .39 & 1.66 & .198 & $1.65(.77-3.55)$ \\
\hline BIS & .73 & .39 & 3.54 & .060 & $2.08(.97-4.47)$ \\
\hline BAI & .59 & .88 & .45 & .505 & $1.80(.32-10.09)$ \\
\hline
\end{tabular}

Note: Bivariate regression Analysis p value <.05.

Table 5: Parameter estimates for logistic model of suicide idea group and comparison group. 
characteristics as well as affective symptoms; depression, anxiety, etc. Depression is closely related with suicide [31,32]. According to the Diagnostic and Statistical Manual of Mental Disorders (DSM-IV), 10$15 \%$ of those who had been diagnosed with depression lost their lives by committing suicide (APA, 1994). Also, suicidal thought and suicidal act are included in the criteria for the diagnosis of depression (APA, 1994), and this indicates that depression has a considerable effect on adolescent suicide. In a study on soldiers, it was reported that the selfesteem was low and the depression level was high when the suicidal intention level was high [33]. Also, in a study on high-risk soldiers, Jeong [34] reported that the group that had actually considered or attempted suicide showed higher depression, despair, and stress levels than the group that had not considered or attempted suicide. These previous study results show that the depression of soldiers who are in military service is a strong prediction factor for the suicide of soldiers. In the present study, it was also found that depression was closely associated with suicidal ideation. Soldiers joining the army are mostly in their early 20s, and are psychologically unstable. For young soldiers, uniform orders and instructions would act as considerable pressure and stress due to the limitation of personal desire. Moreover, soldiers are isolated from their home, and could feel psychological crisis or anxiety due to the concern of being injured or losing their lives in an unfamiliar environment and group life [35]. In a study on high school students, Kim [36] found that for the relation among depression, anxiety, impulsiveness, and suicidal thoughts, both male and female students had more suicidal thoughts when the depression and anxiety were high. In addition, depression and anxiety symptoms are closely related to each other, and commonly coexist. These previous studies suggest that anxiety is a risk factor that could induce suicidal thoughts in military life. As for a study in Korea, Seo et al. [37] performed a survey on 92 soldiers who had visited the department of psychiatry with the chief complaint of psychiatric problems, and reported that there was a significant correlation between adult ADHD and depression symptoms. In addition, Lee et al. [38] reported that $11.8 \%$ of the new patients who had visited military hospitals due to psychiatric and behavioral symptoms and $12.8 \%$ of the total patients showed anxiety disorder. High self-esteem indicates that one regards oneself as a valuable person, and it is a factor that has a major effect on adolescent suicide. Those with high self-esteem can positively perceive a given situation, and thus the risk of extreme behavior such as suicide could decrease [36]. In other words, adolescents with positive and high self-esteem appropriately cope with stress, and deal with a problem based on a positive method; while adolescents with negative and low self-esteem dysfunctionally deal with a problem and could induce suicidal behavior [39]. In a study on the relation among self-esteem, depression, and suicidal intention level for Korean soldiers, it was reported that $39.4 \%$ of the research subjects had low self-esteem, and the self-esteem of the soldiers had a direct or indirect negative effect on depression and suicidal intention [39]. These study results show that high self-esteem is a means to cope with stress, and low self-esteem could be a risk factor for inducing suicidal behavior. V It is known that adolescent suicide is significantly affected by impulsiveness. Adolescents, who are cognitively immature and emotionally unstable, could impulsively attempt suicide. Therefore, impulsive and aggressive tendency and behavior are important factors for predicting suicidal behaviour [40,41]. When stress in daily life is not resolved and is accumulated, soldiers with high impulsiveness show aggressive or impulsive behavior toward others, and this could lead to unexpected behavior such as suicidal incident or desertion.

Suicidal ideation could have an association with ADHD symptoms. ADHD patients show abnormal brain activity relevant to behavioral inhibition, and this lack of self-regulation could result in extreme behavioral problems (e.g., suicidal behavior) along with the difficulties in behavioral regulation for soldiers. It is known that ADHD is a child developmental disorder that occurs before the age of 7 , and it is estimated that the onset of ADHD is mostly before joining the army. Therefore, it is thought that the neuropsychological characteristics of ADHD could have an effect on suicidal ideation. The limitations of this study are as follows. First, this study is based on a self-report questionnaire, and thus the difference in the cognitive ability of the subjects could affect the results. To reduce this effect, socioeconomic condition was used as a control factor during the analysis, but the data for education could not be sufficiently collected. Second, this study is cross-sectional research, and thus a causal relationship between two groups cannot be examined. Only the associations with ADHD, depression, anxiety, self-esteem, and impulsiveness were presented. Third, this study is based on the soldiers residing in one local community. The data of the patient group and the control group were obtained from rural cities with populations of about 500,000 and 200,000, respectively, which belong to rural areas where the populations gradually decrease and the proportion of aged population is high. Accordingly, they could not reflect the characteristics of large cities. In the future, a well-structured case-control study needs to be performed by correcting sex, age, and regional distribution; and the further studies need to be continuously performed by supplementing a number of limitations.

\section{Conclusion}

In this study, for Korean soldiers, the associations with suicidal ideation, depression, anxiety, ADHD, impulsivity and self-esteem were examined. It is thought that effective evaluation and treatment of ADHD symptoms as well as the improvement of affective symptoms, depression, anxiety etc. are needed for soldiers.

\section{Acknowledgements}

The present research was conducted by the research fund of Dankook University in 2015 .

\section{References}

1. Seo HS, Kim JE (2009) The relationship between the navy new generation soldiers' career development and their adjustment in the military-centered on career identity, career decision status, and career preparation behavior. $J$ Adolescent Welfare 11: 81-102.

2. Kim GR, Nam SI, Kim MY (2010) Study on the relationship between superior's level of empathy and subordinate's adaptiveness in barracks. Korean $\mathrm{J}$ Counseling 11: 1537-1549.

3. Hoge CW, Castro CA, Messer SC, McGurk D, Cotting DI, et al. (2004) Combat duty in Iraq and Afghanistan, mental health problems, and barriers to care. $\mathrm{N}$ Engl J Med 351: 13-22.

4. Sareen J, Cox BJ, Afifi TO, Stein MB, Belik SL, et al. (2007) Combat and peacekeeping operations in relation to prevalence of mental disorders and perceived need for mental health care: findings from a large representative sample of military personnel. Arch Gen Psychiatry 64: 843-852.

5. Organization for Economic Cooperation and Development (2010) OECD health data 2009: statistics and indicators for 30 countries. Paris, France.

6. Statistics Korea (2013) Statistics for the causes of death. Seoul, South Korea.

7. Roh MS, Hong JJ, Hae WL, Lee HJ, Han SK, et al. (2006) Suicide-related behaviors among the college students. J Korean Neuropsychiatr Assoc 46: 35-40.

8. Ministry of National Defense (2014) Causes and countermeasures of suicide. Office of the Director General for Legal Affairs Management, Ministry of National Defense.

9. Bernal M, Haro JM, Bernert S, Brugha T, de Graaf R, et al. (2007) Risk factors for suicidality in Europe: results from the ESEMED study. J Affect Disord 101 27-34. 
Citation: Kim NY, Lee PK, Limm MH (2015) Suicidal Idea, ADHD, Depression, Anxiety, Self-esteem and Impulsiveness in Korean Soldiers. J Psychiatry 18: 314 doi: 10.4172/2378-5756.1000314

Page 5 of 5

10. Borges G, Angst J, Nock MK, Ruscio AM, Walters EE, et al. (2006) A risk index for 12-month suicide attempts in the National Comorbidity Survey Replication (NCS-R). Psychol Med 36: 1747-1757.

11. Cho SC, Kim JW, Choi HJ, Kim BN, Shin MS et al. (2008) Associations between symptoms of attention deficit hyperactivity disorder, depression, and suicide in Korean female adolescents. Depress and Anxiety 25: 142-146.

12. Agosti V, Chen $Y$, Levin FR (2011) Does attention deficit hyperactivity disorder increase the risk of suicide attempts? J Affect Discord133:595-599.

13. Kessler RC, Adler LA, Barkley R, Biederman J, Conners CK, et al. (2005) Patterns and predictors of attention-deficit/hyperactivity disorder persistence into adulthood: results from the national comorbidity survey replication. Biol Psychiatry 57: 1442-1451.

14. Ban GH, Jo AL (2002) Review: Attention Deficit-Hyperactivity Disorder in Adults. Kyunghee Med 18: 143-157.

15. Jang MJ (2004) Characteristic and Educational intervention strategy of Adult with Attention-Deficit/Hyperactivity. J Education Development 20: 43-57.

16. Ban GH, Son SJ, Park YC, Cho AR, Park JK (2006) Reviews: Occupationlal and Military Issues of Adult with Attention-Deficit/Hyperactivity Disorder. Kyunghee Med 22: 112-116.

17. Beck AT, Kovacs M, Weissman A (1979) Assessment of suicidal intention the Scale for Suicide Ideation. J Consult ClinPsychol 47: 343-352.

18.

19. Shin MS (1993) The empirical study to suicide mechanism: the validation selfescafe scale. Yeonse University, Seoul, South Korea.

20. Murphy K, Barkley R (1995) Preliminary normative data on DSM-IV criteria for adults. The ADHD Report 3: 6-7.

21. Kim EJ (2003) The validation of Korean Adult ADHD Scale. Korean J ClinPsychol 22: 897-911.

22. Beck AT, Ward CH, Mendelson M, Mock J, Erbaugh J (1961) An inventory for measuring depression. Arch Gen Psychiatry 4: 561-571.

23. Lee Yh, Song JY (1991) A study of the reliability and validity of the BDI, SDS, and MMPI-D scales. Korean J ClinPsychol 10(1):98-113.

24. Beck AT, Epstein N, Brown G, Steer RA (1988) An inventory for measuring clinical anxiety: psychometric properties. J Consult ClinPsychol 56(6): 893-897.

25. Yook SP, Kim ZS (1997) A clinical study on the Korean version of Beck Anxiety Inventory: comparative study of patient and non-patient. Korean J ClinPsychol 16(1): 185-197.

26. Lee YH (1993) The Relations between attribution style, life events, event attribution, hopelessness and depression. Ph.D. Thesis: Graduate School Seoul National University, Seoul.
27. Choi $\mathrm{OH}$ (2007) The effects that admiring parents group training program gives to the self-respect of mothers and to the mother-child relationship the mother perceives. M.S. Thesis, Graduate School of Public Policy, Sogang University, Seoul.

28. Yoo J, Yang W, Lee K, Lee S, Lee CS, et al. (2003) Gender difference in selfesteem of medical students. Korean J Medl Education 15(3): 241-248.

29. Lee HS (1992) Impulsivity Test. Seoul Korean Guidance, Seoul.

30. Lee SS (2000) A Study of the relationship between addiction in computer game and emotional traits of adolescent. Seoul Women University, Seoul.

31. Brent DA, Perper JA, Moritz GA, IIman C, Roth C, et al. (1993) Psychiatric risk factors of adolescent suicide: a case control study. J Am Acad Child Adol Psychiatry 32: 521-529.

32. Kelly TM, Lynch KG, Donovan JE, Calrk DB (2001) Alcohol use disorders and risk factor interventions for adolescent suicide ideation and attempts. Suicide and Life Threatening Behavior 31: 181-193.

33. Jeong MK, Ko KS (2009) The effect of soldiers' self-esteem and depression on suicidal ideation-Verifying mediation effect of depression. Korean $\mathrm{J}$ Social Welfare Studies 40: 453-483.

34. Jeung SY, Lee DG (2011) Psychological Characteristics of Soldiers at Suicide Risk. Korean J Counseling 12: 897-914.

35. Lee Jh, Cho JY 1999) Anxiety, Depression and Impulsiveness according to Military Service Duration in Army-Enlisted Males. J Korean NeuropsychiatrAssoc 38: $966-972$.

36. Kim GS, Jeon YS (2012) The Effects of Depression, Anxiety, and Impulsiveness on Suicidal Thoughts among Adolescents. Korean J Hum Ecol 21; 903-913.

37. Seo JY, Park CS, Kim BJ, Cha BS, Lee CS, et al. (2011) Effect of Symptoms of Adult Attention Deficit Hyperactivity Disorder on Stress and Depressive Symptoms in Soldiers. Anxiety and Mood 7: 101-106

38. Lee SY, Yoon CY, Min JA, Lee CU, Park DU, et al. (2014)The Incidence Rate of Anxiety Disorders in the Korean Military. Anxiety and Mood 10: 59-67.

39. Kim BY (2009) A Meta-Analysis of Variables Related to Suicidal Ideation in Adolescents. Ph.D. Thesis: Graduate School, Chonnam National University, Kwanju.

40. Hong YS, Jeon SY (2005) The Effects of Life Stress and Depression for Adolescent Suicidal Ideation. Mental Health and Social Work 19: 125-149.

41. Hong JD, Yang NM (2013) An effect of soldier stress on suicidal ideation: Selfesteem, alienation, frustration mediating effect. Korea J Counseling 14: 14231441.

42. Wetzler S, Asnis MD, Hyman RB, Virtue C, Zimmerman J, et al. (1996) Characteristics of suicidality among adolescents. Suicide Life Threaten Behav 26: $37-45$. 